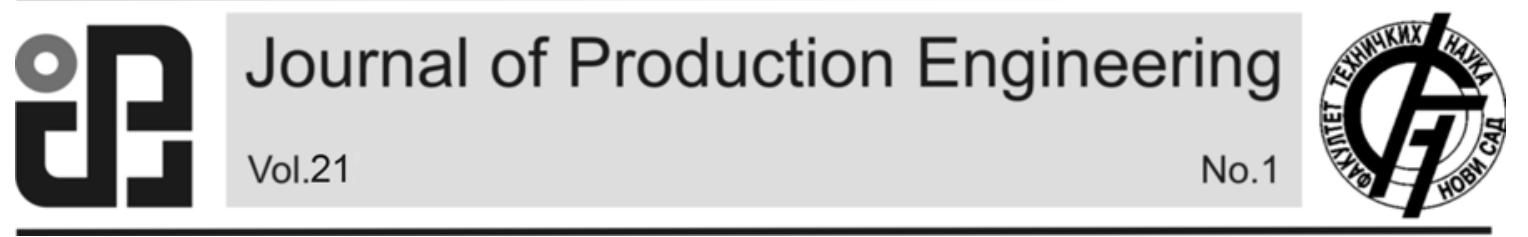

JPE (2018) Vol.21 (1)

Terzić, S., Lazarević, D., Nedić, B., Šarkoćević, Ž., Dedić, J.

Original Scientific Paper

\title{
MACHINING CONTACT AND NON-CONTACT INSPECTION TECHNOLOGIES IN INDUSTRIAL APPLICATION
}

Received: 21 February 2018 / Accepted: 22 April 2018

\begin{abstract}
Even though coordinate measuring machines (CMM) still achieve the most accurate measurement results, non-contact (optical) measuring systems are applied more and more in industry. The reasons of using optical scanners are in the higher speed of acquisition, higher density of data-points and better surface description, the ability to scan complex and non-rigid surfaces etc in comparison to contcact devices. This paper gives a review of state-of-the-art measuring contact and non-contact inspection technologies in industrial applications. Listed are the devices, principles and systems that are used at the data-acquisition (triangulation, time-of-flight and interferometry). The description of contact measuring machines (portable CMM and stationary CMM) and devices for non-contact scanning (laser scanner, structured light scanner and CT scanner) is given, and their advatages and disadvantages are mentioned with corresponding literature review.
\end{abstract}

Key words: CMM, scanner, measurement, inspection

Primena kontaktnih i bezkontaktnih inspekcionih tehnologija u industriji. Iako koordinatne merne mašine (CMM) još uvek postižu najtačnije rezultate merenja, u industriji se sve češće primenjuju bezkontaktni (optički) merni sistemi. Razlozi korišćenja optičkih skenera se nalaze u većoj brzini akvizicije, većoj gustini podataka-tačaka i boljem opisu površine, mogućnošću skeniranja složenih i mekih površina itd. u odnosu na kontaktne uređaje. Ovaj rad daje pregled stanja savremenih mernih kontaktnih i bezkontaktnih inspekcioinih tehnologija koje se primenjuju u industriji. Navedeni su uređaji, principi i sistemi koji se primenjuju pri akviziciji podataka (triangulacija, time-offlight i interferometrija). Dat je opis kontaktnih mernih uređaja (prenosivih CMM $i$ stacionarnih CMM) i uređaja za bezkontaktno skeniranje (laserskih skenera, skenera strukturiranog svetla i CT skenera) $i$ navedene su njihove prednosti i nedostaci uz odgovarajući pregled literature.

Ključne reči: CMM, skener, merenje, inspekcija

\section{INTRODUCTION}

Traditionally, the measurement of dimensional and shape precision in industrial practice is performed by conventional methods such as a contact method using coordinate measuring machines (CMM). Even though these machines provide one of the most accurate results [1], they cannot be used in some cases. An example may be measurement of surfaces with very complex shapes. Furthermore, the point-to-point contact process is very time consuming for large $3 \mathrm{D}$ shape [2].

That is the reason why laser and optical measurement systems, so called 3D scanners, are used more and more often in industry. These scanners digitise the part, and the inspection itself is performed on a virtual model obtained by means of the digitisation process $[3,4]$ comparing with an ideal 3D CAD model in any inspection software. Inspection using these systems offer several crucial advantages such as fast measurement of parts, even with complex shapes, high data density and, above all, independence of results on part's rigidity. Due to the overall description of a measured part, it also allows to perform complex and objective analysis. In spite of the well-known advantages that these systems offer, there are also some difficulties, such as the undefined and nonstandardized accuracy [5] and measuring uncertainty [6] when compared with traditional inspection systems based on touch-trigger probes. Computed Tomography (CT) should be mentioned which is more and more used in industry, and (CT) is the only technology that is able to measure the inner as well the outer geometry of a component or assembly without the need to cut it through and damage it. The number of industrial applications of CT is large and rapidly increasing.

\section{MEASUREMENT PROCEDURES}

Measuring and inspection technologies play a key role as a control tool in manufacturing. Accurate measurements are important in being able to monitor production processes and ensure conformity to design specifications [7].

Three types of measurement can be differentiated $[8,9,10,11]$ :

- in situ measurement,

- in-process measurement and

- on-machine measurement.

In situ measurement encompasses all the measurement techniques which are performed in the machine environment. Here the non-contact techniques are more and more used, as they represent a good compromise between rapidity and resolution.

During in-process measurement, the manufacturing process is not stopped, and inspection is carried out simultaneously with part machining. In this case, the 
measurement is not necessarily the geometry of the part but can be another characteristic such as cutting forces, spindle vibrations, temperature and so on.

On the other hand, on-machine measurement is performed while the part is still located in the machinetool but while the machining process is stopped. Here, the machine-tool holds the sensor, a touch probe [12], an optical sensor or a combination of different sensors, and allows sensor displacements as on classical CMM.

\section{ACQUISITION DEVICES, PRINCIPLES AND SYSTEMS}

A 3D data-acquisition device is an instrument that collects $3 \mathrm{D}$ coordinates of a given region of a surface [13]. However, different technical principles can be applied in measuring the elements needed to compute a 3D geometry.

Systems for data-acquisition are classified on the basis of technical principles that are used on [14]: contact and noncontact devices. Non-contact devices uses mediums like light, sound or magnetic fields, while contact devices touch the object surface using a mechanical probe. (tactile method).

Non-contact devicesare further classified to [15]: passive and active systems.

A passive system uses shape-from-shading, shapefrom-motion, or passive stereo vision to acquire 3D data. The advantages of a passive system are [16]:

- it is less sensitive to environment; and

- it is suitable for a mobile vision platform and requires no external energy source.

Shape-from-shading and shape-from-motion methods are not well suited for general 3D data acquisition because of [16]:

- sensitivity to the illumination and surface

reflectance properties of an object,

- limited ability to cope with non-uniform surface textures and

- the difficulty to infer absolute depth.

Passive stereo vision has a critical issue of finding the pixel correlations of two images.

Active systems, that are classified as non-contact systems mostly used in meteorological applications, can be further classified in terms of underlying physical principles: triangulation, time-of-flight or laser pulse, and interferometry.

Triangulation is based on the principle of triangulating a measurement spot on the object from a physically separate camera optical source and detector. By simple geometry, the $(\mathrm{x}, \mathrm{y}, \mathrm{z})$ coordinates of the illuminated spot on the object are calculated [17]. Triangulation-based sensors can be single-point (Fig. 1. a) or slit (Fig. 1. b). A single-point sensor acquires range information point by point, whereas a slit scanner allows the projection of a laser line and the simultaneous detection of a complete profile of points [16].

Time-of-flight or laser pulse scanners (Fig. 2) work on the principle that the surface of an object reflects light back towards a receiver which then measures the time (or phase difference) between transmission and reception. The range is measured as a direct consequence of the propagation delay of electromagnetic wave. Two of the main advantages of the time-of-flight method are that the transmitter and receiver beams are coaxial and that the measurement accuracy does not depend on distance (which is not the case with triangulation, for example) [19]. Fig. 2. show an time-of-flight based system.

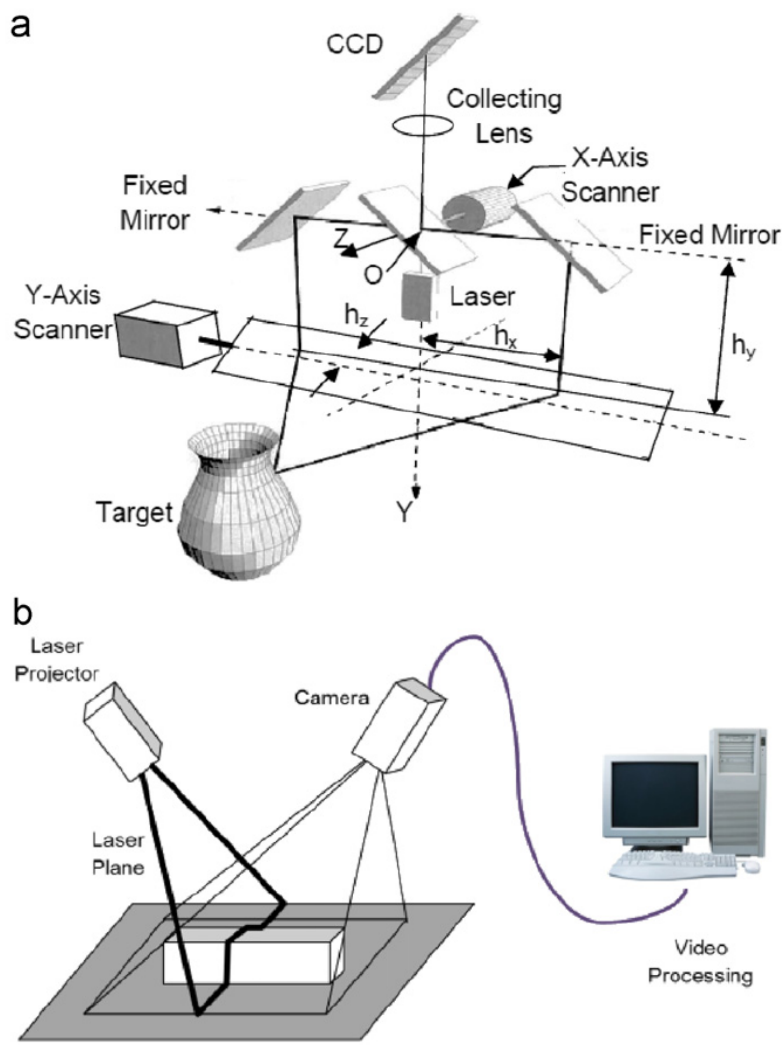

Fig. 1.Triangulation principle [18] (a) Single-point sensor and (b) slit sensor.

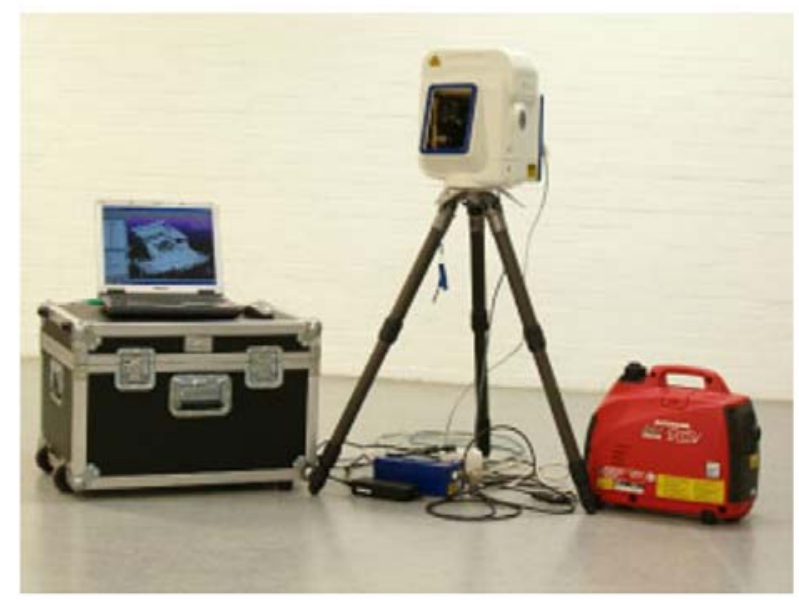

Fig. 2. Time-of-flight based system [20]

Interferometric methods operate by projecting a spatially or temporally varying periodic pattern onto a surface, followed by mixing the reflected light with a reference pattern. The reference pattern demodulates the signal to reveal the variation in surface geometry. The measurement resolution is very high, since it is a fraction of the wavelength of the laser radiation. For this reason, surface quality control and microprofilometry are the most explored applications. 
Use of multiple wavelengths and of double heterodyne detection lengthens the non-ambiguity range [21]. Fig. 3. shows an image example acquired by an interferometry sensor.
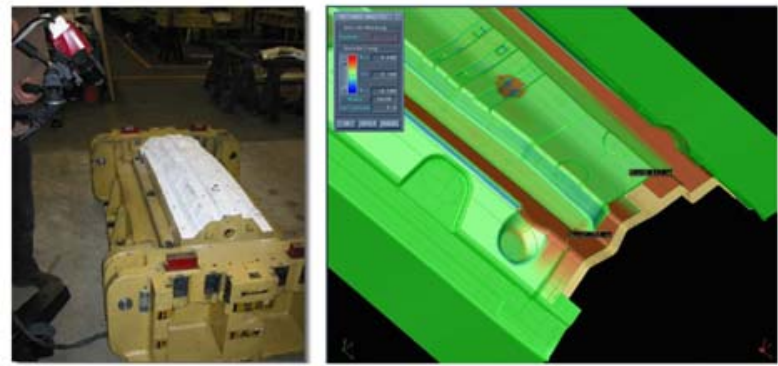

Fig. 3. Interferometric scanner and an image example acquired by an interferometry sensor [16]

\subsection{Coordinate Measuring Machines}

In co-ordinate metrology the actual shape and dimensions of an item are measured, and compared against desired 3D shape and dimensions, as might be specified on a part drawing. Coordinate measuring machines (CMMs) is an electromechanical system that has been designed to evaluate relevant dimensions of an item against a required standard.

CMMs are widely employed in most areas of modern advanced manufacturing industry, as well as in many other fields that require high quality dimensional inspection, including dimensional measurement, angularity or orientational measurement, profile measurement, depth mapping, digitizing, reverse engineering, rapid prototyping etc.

CMM can be performed in two main varieties: portable and stationary CMMs.

Portable CMMs (Fig. 5), which typically are stationed on an arm or are observed by a tracking device, are, as the name implies, highly portable and can be moved to a part rather than the other way around as with stationary CMMs. They are manually operated, and lower accuracy than stationary CMMs, but also come at a much reduced cost. Use of portable CMMs requires a lot less training, can be used on very large parts without requiring complex set up, and it is easy to add additional portable CMMs to increase throughput.

Stationary CMMs (Fig. 6), are typically very large installations - gantry, bridge and horizontal systems that are highly accurate, expensive and much slower compared to other methods. These CMMs have zero portability and the part being measured has to be ported to the CMM itself, not vice versa. A number of different physical configurations exist for the mechanical structure of the stationary CMM; these include: cantilever, moving bridge, fixed bridge, horizontal arm, gantry, and column mechanical structures.

The tip of the probe in the CMM is usually a ruby ball. Ruby is a form of corundum (aluminium oxide) with high hardness for wear resistance, and low density for minimum inertia, thus making it ideal for probing applications. Probes can be single or multiple tip. The most common probe design is the touch-trigger type, which actuate when the probe makes contact with the item's surface.

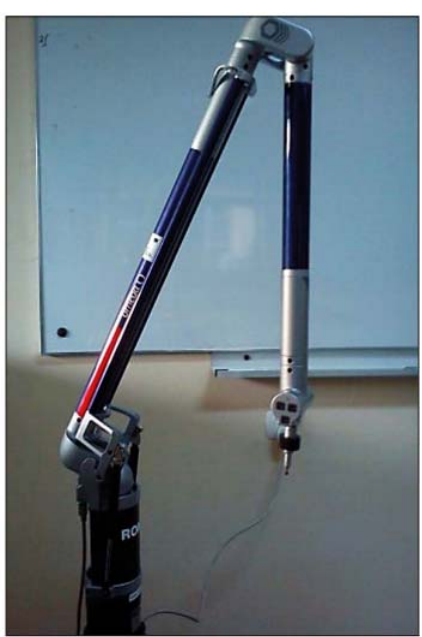

Fig. 5. Portable CMMs [22]

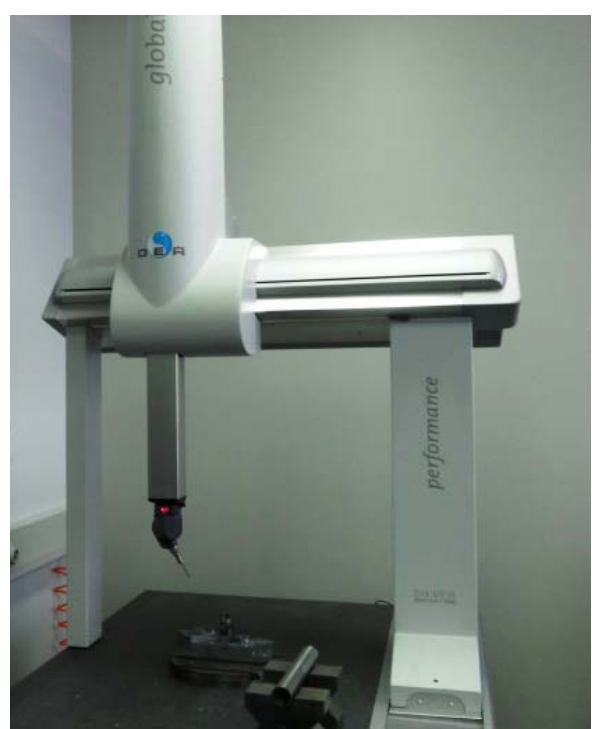

Fig. 6. Stationary CMMs

Stationary CMMs have the disadvantage of being fixed in one place, being very slow and quite costly. Secondly, data capture is slow.

CMM control (probe positioning) may be accomplished via methodologies that use manual drive; manual drive with computer-assisted processing; motor drive with computerassisted data processing; or direct computer control with computer assisted data processing.

In the case of CMMs using direct computer control with computer assisted data processing capabilities, two principle methods of programming may be outlined: Manual lead-through (where the operator leads the CMM probe through the various motions that are required of it for a particular workpart, while the points and locations are recorded into programme memory) and Off-line programming (where the programme is prepared based on the workpart drawing, and then downloaded to the CMM controller for execution).

As requirements on complexity and accuracy of dimensional metrology increases, multisensor measurements combining different sensors are implemented to achieve both holistic geometrical measurement and improved reliability of measured data 
[23]. Brojni su radovi na kombinaciji tuch-trigger probe i optičkih senzora na CMM, između ostalog [24,25,7].

Performance of CMMs has been the subject of very extensive research and standardization among other things $[26,27,28,29,30]$.

\subsection{Nonconcact scanning devices}

Noncontact scanning systems (scanners) are becoming more present in the industry every day. These systems allow a significant reduction in manufacturing costs, mainly due to the important decrement in the inspection time. They enable obtaining a great amount of data that provides very good levels of quality in results. In spite of the wellknown advantages that these systems offer, there are also some difficulties, such as the undefined and nonstandardized accuracy when compared with traditional inspection systems based on touch-trigger probes [5]. Noncontact scanning systems range across laser scanners, structured light scanners and industrial CT scanners. All of them capture the "shape" of the part so that measurements can be made and analyzed using inspection software. They are (except for CT scanners) highly portable and flexible to use, with no or very few compensations for the data being collected. They avoid possible surface damage that can be caused upon contact [31]. Also, in a case when the parts are made from materials with elastic properties application of contact methods for threedimensional digitization is not appropriate [32].

Laser scanners. Laser scanners (Fig. 7) use laser light to create the 3-D shape of the part as a point cloud. They tend to be very flexible - you can mount them to CMMs and portable CMMs - and can be handheld or mounted on tripods. Laser light causes inherent measurement noise and diffusion from the laser light limits the resolution possible, and laser based systems typically have difficulties measuring highly reflective surfaces. Camera resolution is always better than laser coherence. Your use of these scanners should be made based on the available resolution of a scanner compared to your tolerance requirements on the shop floor.

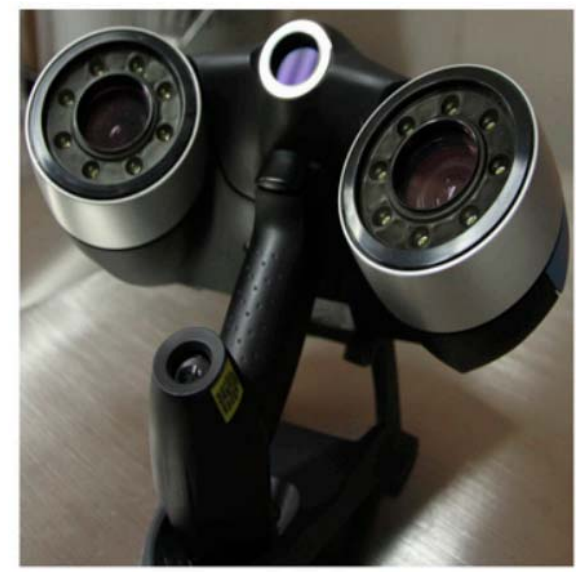

Fig. 7. Handheld laser scanner [33]

Structured Light Scanners. A structured light scanner (Fig. 8) uses projected light patterns and a camera system to record the deviations of the light to record the 3-D shape of the part. Available in multiple shades of light, these scanners are usually more accurate than laser scanners, due to a markedly lower measurement noise. In addition, they can deal with shiny parts. The combined light and camera technology delivers much greater accuracy and also means much heavier datasets to deal with. They are also less flexible, needing to be mounted and calibrated on tripods or robots.

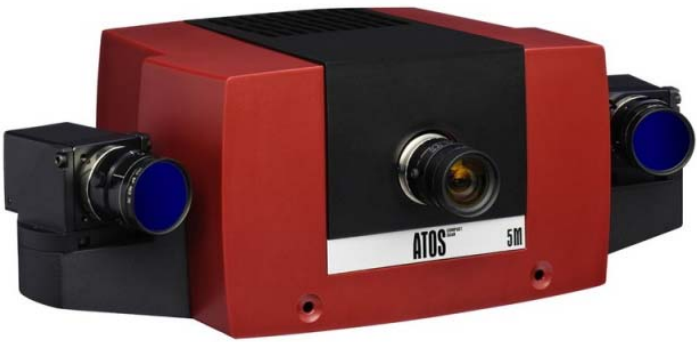

Fig. 8. Structured light scanner

Industrial CT Scanners. The first CT scanner was built for medical imaging by Nobel Prize winner Hounsfield in 1969 [34]. Since 1980, CT became popular for material analysis and non-destructive testing and detecting material defects. In 2005, CT technology entered the application field of dimensional metrology, as alternative to tactile or optical 3D coordinate measuring systems. CT (Fig. 9) is similar to magnetic resonance imaging (MRI), but where MRI uses non-ionizing radio frequency radiation to detect the magnetic resonance of hydrogen molecules, CT uses ionizing radiation and measures the absorption of X-rays.

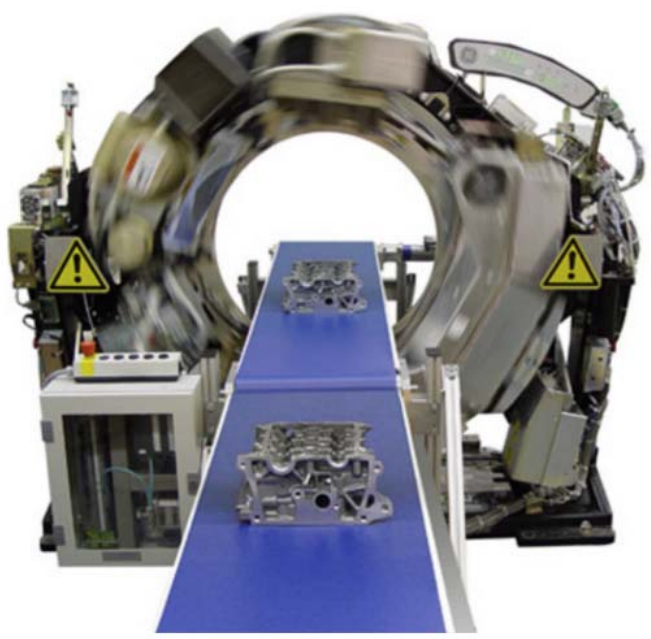

Fig. 9. CT inspection system with detector who rotates around the workpieces on a conveyor belt [36]

Typical areas of use for CT in industry are in the detection of flaws such as voids and cracks, and particle analysis in materials. In metrology, CT allows measurements of the external as well as the internal geometry of complex parts. So far, CT metrology is the only technology able to measure as well the inner as the outer geometry of a component without need to cut it through and destroy it [35]. CT scanners have limitations on what materials can be scanned so that needs to be carefully checked against requirements. 


\section{CONCLUSION}

Non-contact systems for measurement and scanning are getting more and more common in industrial measurement with every day. In spite of measurement accuracy, the inspection using CMM has certain limits. These limits are: low speed scanning (the more complex and bigger the part is, the longer the scanning is), reduced availability of certain surfaces like cylinders, difficulty in measuring flexible materials etc. Non-contact measuring techniques, essentially optical techniques, overcome these limits, while with the development of their hardware their accuracy is growing, so they tend to take the predominance over conventional measuring devices.

In the paper the review of state-of-the-art measuring contact and non-contact inspectional technologies that are used in industry are given. Listed are the measuring procedures (in situ measurement, in-process measurement and on-machine measurement), so from the given information it is concluded that on-machine measuring is becoming the desirable measuring equipment.

The classification of devices for data-acquisition on the technological principle basis (contact and noncontact) is given. The principle of measuring active systems that are most commonly used in industrial measurement (triangulation, time-of-flight and interferometry) is described. The CMMs that build as stationary and portable, as well as some non-contact devices (laser scanner, structured light scanner and industrial CT scanner) are described, and their advatages and disadvantages as well as possibilities of using multisensory technology are given.

The goal of the paper is to research literature related to the measuring equipment, i.e. connection of partial elements from a complex process of measuring and the understanding of integration of contemporary systems for scanning, which development is intensive, in a process of measuring. Further research will advance in the direction of researching software that is along the listed hardware.

\section{REFERENCES}

[1] Flack, D.: CMM verification (National Physical Laboratory). Measurement Good Practice Guide. No. 42, ISSN 1368-6550, 2011.

[2] Xu, J., Xi, N., Zhang, C., Zhao J., Gao B., Shi, Q.: Rapid $3 D$ surface profile measurement of industrial parts using two-level structured light patterns, Optics and Lasers in Engineering, 49, p.p. 907-914, 2011.

[3] Harding, K.: Handbook of Optical Dimensional Metrology. Boca Raton: CRC Press, 2013.

[4] Zhang, S.: Handbook of 3D Machine Vision: Optical Metrology and Imaging. Boca Raton: CRC Press, 2013.

[5] Martínez, S., Cuesta, E., Barreiro, J., Álvarez, B.: Analysis of laser scanning and strategies for dimensional and geometrical control, Int $\mathrm{J} \mathrm{Adv}$ Manuf Technol, 46, p.p. 621-629, 2010.

[6] Mendricky, R.: Determination Of Measurement
Accuracy Of Optical 3d Scanners, Mm Science Journal, p.p. 1565-1572, 2016.

[7] Zhao, H., Kruth, J.-P., Van Gestel, N., Boeckmans, B., Bleys, P.: Automated dimensional inspection planning using the combination of laser scanner and tactile probe. Measurement, 45, p.p. 10571066, 2012.

[8] Liu, Z.-Q.: Repetitive measurement and compensation to improve workpiece machining accuracy, International Journal of Advanced Manufacturing Technology, 15, 85, 1999.

[9] Vacharanukul, K., Mekid, S.: In-process dimensional inspection sensors. Measurement 38(3), p.p. 204-218, 2005.

[10]Quinsat, Y., Dubreuil, L., lartigue, C.: A novel approach for in-situ detection of machining defects, Int J Adv Manuf Technol, 90, p.p. 16251638, 2017.

[11] Whitehouse, D.: Surfaces and Their Measurement, London: Hermes PentonLtd, 2002.

[12] Mears, L., Roth, J., Djurdjanovic, D., Yang, X., Kurfess, T.: Quality and inspection of machining operations: CMM integration to the machine tool, ASME J Manuf Sci Eng, 131(5), p.p. 1-13, 2009.

[13]Boehler, W., Marbs, A.: 3D scanning instruments. In: Proceedings of the International workshop on Scanning for Cultural Heritage Recording, Corfu, Greece, Sept. 1-2, p.p. 9-12, 2002.

[14] Varady, T., Martin, R., Cox, J.: Reverse engineering of geometric models - an introduction. Computer-Aided Design, 29(4), p.p. 255-68. 1997.

[15] Isgro, F., Odone, F., Verri, A.: An open system for $3 D$ data acquisition from multiple sensors. In: Proceedings of the seventh international workshop on Computer Architecture for Machine Perception (CAMP’05), Universita di Genova, Italy, July 4-6, p.p. 52-57, 2005.

[16]Bi, Z.M., Wang, L.: Advances in $3 D$ data acquisition and processing for industrial applications, Robotics and Computer-Integrated Manufacturing 26, p.p. 403-413, 2010.

[17] Scott, WR., Roth, G., Rivest, J-F.: View planning for automated three-dimensional object reconstruction and inspection. ACM Computing Surveys, 35(1), p.p. 64-96, 2003.

[18]Blais, F.: Review of 20 years of range sensor development. Journal of Electronic Imaging, 13(1), p.p. 231-40, 2004.

[19] Kilpelä, A.: Pulsed Time-Of-Flight Laser Range Finder Techniques For Fast, High Precision Measurement Applications, Academic Dissertation to be presented with the assent of the Faculty of Technology, University of Oulu, for public discussion in Raahensali (Auditorium L10), Linnanmaa, 2004.

[20]Kersten, Th., Sternberg, H., Mechelke, K., Acevedo Prado, C.: Terrestrial laserscanning system MENSI GS 100/GS 200 - accuracy tests, experiences and projects at the Hamburg University of Applied Sciences. Panoramic Photogrammetry Workshop 2004, organized by TU Dresden, University of Stuttgart, and ISPRS WG V/1. February, p.p. 19 - 22, 2004. 
[21] Sansoni, G., Trebeschi, M., Docchio, F.: State-ofThe-Art and Applications of 3D Imaging Sensors in Industry, Cultural Heritage, Medicine, and Criminal Investigation, Sensors, 9, p.p. 568-601, 2009.

[22] Kupiec, M.: Coordianate measurment systems CMM and CMA - characteristc and methods of their accuracy evaluation, Advances in Science and Technology Research Journal Volume 6, No. 16, Dec., pp. 18-23, 2012.

[23] Weckenmann, A., Jiang, X., Sommer, K.D., Neuschaefer-Rube, U., et al.: Multisensor data fusion in dimensional metrology, CIRP Ann. Manuf. Technol, 58 (2), p.p. 701-721, 2009.

[24] Carbone, V., Carocci, M., Savio, E., Sansoni, G., et al.: Combination of a vision system and $a$ coordinate measuring machine for the reverse engineering of freeform surfaces, J. Adv. Manuf. Technol. 17 (4), p.p. 263-271, 2001.

[25]Huang, Y., Qian, X.: A dynamic sensing-andmodeling approach to three-dimensional pointand-area-sensor integration, J. Manuf. Sci. Eng. 129 (3), p.p. 623-635, 2007.

[26] Bosch, J.A.: Coordinate measuring machines and systems, I M. Dekker, CRC Press, (ed.) 1995.

[27] Kunzrnann, H., Waldele, F.: Performance of CMMs, Annals of the CIRP, Vol. 37/2, pp. 633640, 1988.

[28] Wilhelm, R. G., Hocken, R., Schwenke, H.: Task specific uncertainty in coordinate measurement. Annals of the CIRP Vol. 52/2., p.p. 553-563, 2001.

[29]ASME/ANSI, B89.4.1:1997, Methods for Performance Evaluation of Coordinate Measuring Machines.

[30]ISO 10360-2:2009: Geometrical product specifications (GPS) - Acceptance and reverification tests for coordinate measuring machines (CMM) - Part 2: CMMs used for measuring linear dimensions, Geneva, Switzerland

[31] http://www.qualitymag.com/articles/91150contact-vs-noncontact-measurement-for-computeraided-inspection, 6.3.2018.

[32] Topcic, A., Tufekcic, Dž., Fajic, A., Cerjakovic, E.: Implementation of Three Dimenzional - 3DP printing process in casting, 5th international symposium, Faculty of Technical Science Novi Sad, Serbija. 2008.

[33] Ameen, W., Al-Ahmari, A. M., Mian, S. H.: Evaluation of Handheld Scanners for Automotive Applications, Appl. Sci., 8, 217, 2018.

[34] Kruth, J-P., Bartscher, M., Carmignato, S., Schmitt, R., De Chiffre, L., Weckenmann, A.: Computed Tomography for Dimensional Metrology. CIRP Annals 60(2), p.p. 821-842. 2011.

[35] De Chiffre, L., Carmignato, S., Kruth, J.-P., Schmitt, R., Weckenmann, A.: Industrial applications of computed tomography, CIRP Annals - Manufacturing Technology 63, p.p. 655677, 2014.

[36] Brunke, O., Hansen, F., Stuke, I., Butz, F., Jeltsch, F.: A New Concept for Highspeed Atline and
Inlinect for up to 100\% Mass Production Process Control Allowing both, 3D Metrology and Failure Analysis. Proc. of Int. Conf. on Industrial Computed Tomography - iCT 2012, Wels, Austria, 19-21 September, 2012.

Authors: Professor Terzić Slavica; Professor Dedić Jasmina, Secondary school „Grigorije Božović“ Zubin Potok, Jelene Anžujske 17, 38228 Zubin Potok, Serbia. Assist. Dragan Lazarević, PhD; Professor Živče Šarkoćević, PhD, University of Priština, Faculty of Technical Sciences, Kneza Miloša 7, 38220 Kosovska Mitrovica, Serbia. Professor Bogdan Nedić, PhD, University of Kragujevac, Faculty of Engineering, Sestre Janjić 6, 34000 Kragujevac. Serbia

e-mail: tslavica172@gmail.com jasminavdedic@hotmail.com dragan.lazarevic@pr.ac.rs zivce.sarkocevic@pr.ac.rs nedic@kg.ac.rs 